\title{
Updates on the molecular genetics of primary congenital glaucoma (Review)
}

\author{
CHEN LING ${ }^{1,2^{*}}$, DINGDING ZHANG ${ }^{1,2^{*}}$, JING ZHANG $^{3^{*}}$, HUANXIN SUN $^{4}$, QIU DU ${ }^{5}$ and XUEFEI LI ${ }^{5}$ \\ ${ }^{1}$ Sichuan Provincial Key Laboratory for Genetic Disease, Sichuan Provincial People's Hospital, School of Medicine, \\ University of Electronic Science and Technology of China; ${ }^{2}$ Chinese Academy of Sciences Sichuan Translational Medicine \\ Research Hospital; ${ }^{3}$ Department of Thoracic Surgery, Sichuan Provincial People's Hospital, University of Electronic \\ Science and Technology of China, Chengdu, Sichuan 611731; ${ }^{4}$ Department of Immunology, North Sichuan Medical College, \\ Nanchong, Sichuan 637100; ${ }^{5}$ College of Medical Technology, Chengdu University of \\ Traditional Chinese Medicine, Chengdu, Sichuan 610072, P.R. China
}

Received November 5, 2019; Accepted April 1, 2020

DOI: $10.3892 /$ etm.2020.8767

\begin{abstract}
Primary congenital glaucoma (PCG) is one of the primary causes of blindness in children and is characterized by congenital trabecular meshwork and anterior chamber angle dysplasia. While being a rare condition, PCG severely impairs the quality of life of affected patients. However, the pathogenesis of PCG remains to be fully elucidated. It has previously been indicated that genetic factors serve a critical role in the pathogenesis of PCG, although patients with PCG exhibit significant genetic heterogeneity. Mutations in the cytochrome P450 family 1 subfamily B member 1 gene have been implicated in PCG and further genes that have been reported to be involved in PCG are myocilin, forkhead box $\mathrm{C1}$, collagen type I $\alpha 1$ chain and latent transforming growth factor $\beta$ binding protein 2 . The present review aims to provide an up to date understanding of the genes associated with PCG and the use of molecular technologies in the identification of such genes and mutations. This may pave the way for the development of preventative methods, early diagnosis and improved therapeutic strategies in PCG.
\end{abstract}

Correspondence to: Professor Dingding Zhang, Sichuan Provincial Key Laboratory for Genetic Disease, Sichuan Provincial People's Hospital, School of Medicine, University of Electronic Science and Technology of China, 2006 XiYuan Road, GaoXin Zone, Chengdu, Sichuan 611731, P.R. China

E-mail: zhangdd25@126.com

*Contributed equally

Key words: primary congenital glaucoma, genes, mutation, sequencing

\section{Contents}

1. Introduction

2. Clinical characteristics of PCG

3. Treatment strategies for PCG

4. Recent advances in technologies for PCG-associated gene identification

5. Genetic aspects and mutations in genes associated with PCG

6. Conclusions

\section{Introduction}

Glaucoma is a disorder of progressive death of retinal optic neurons, which results in a characteristic appearance of the optic disc and visual loss (1). Glaucoma is estimated to affect $\sim 66$ million individuals worldwide, with glaucoma patients in Asia accounting for almost $50 \%$ of all cases $(2,3)$. A total of $1.2 \%$ of children in Britain suffer from glaucoma, and in India, $3-7 \%$ of children suffer from this disease $(4,5)$. Based on the modern classification system, primary glaucoma may be classified into three different subtypes: Primary open-angle glaucoma, primary angle-closure glaucoma and primary congenital glaucoma (PCG). PCG is a rare form accounting for $1-5 \%$ of all cases of glaucoma (6). In addition, PCG is common, with a prevalence of $>32 \%$ in children who suffer from glaucoma (7). The overall incidence of PCG in Denmark is 4.8 in 100,000 live births (8).

PCG is a serious form of glaucoma, which results in congenital developmental abnormalities with optic nerve degeneration and dysplasia of the anterior segment that may even contribute to irreversible blindness. The onset of PCG may be as early as at birth but may potentially manifest within the first 3 years of life (9). Numerous patients have congenital anomalies in the anterior chamber angle architectures when they are born. The incidence of PCG varies in different countries and by ethnicity. PCG occurs in 1:30,000 individuals in Australia (10) and 1:24,941 individuals in China (11). In western 
countries, the incidence ranges between 1:10,000 and 1:70,000 individuals (12). In the highly consanguineous population of Saudi Arabia, a minimum incidence of 1:2,766 has been reported, while it is markedly higher in Southern India and in the Roma population of Slovakia, where its incidence lies between 1:1,250 and 1:3,300 (13). Therefore, the occurrence of this disease appears to be associated with consanguinity. The prevalence of PCG-associated blindness is $\sim 10 \%$ in Douala, $4.2 \%$ in southern India and $6.3 \%$ in China (14). However, the pathogenesis of this disease remains to be fully elucidated and requires further study.

Early diagnosis and prompt treatment are particularly necessary for patients with PCG to maintain visual function throughout their lives. Identifying the pathogenic mechanism of PCG may assist in the development of treatments to slow down the development of consequent blindness. The pathogenic factors of PCG primarily involve two aspects, environmental and heredity. Environmental factors include viral and parasitic infections and the use of drugs by the mother during pregnancy. Patients with PCG frequently have a family history of occurrence and familial aggregation. In recent years, specific genes associated with PCG have been identified through the use of molecular genetics-based techniques, including linkage analysis, exon sequencing and comparative genomic hybridization, e.g. cytochrome P450 family 1 subfamily B member 1 (CYP1B1), myocilin (MYOC), forkhead box C1 (FOXC1) and collagen type I $\alpha 1$ chain (COL1A1). The present review is focused on the genetic aspects of PCG occurrence and screening of PCG-associated genes.

\section{Clinical characteristics of PCG}

Due to the limited cooperativeness of children, no obvious symptoms may be detected at the early stage and examination equipment is mainly designed for adults; missed or delayed diagnosis or misdiagnosis are therefore common (15). Patients with PCG always have an abnormal structure of the trabecular meshwork (TM) and anterior chamber angle, and they present with an increase of the intraocular pressure and a further extension of sclera, optic nerve and associated structures. 'Bull's eye' is a typical clinical feature of PCG. The other common symptoms associated with PCG include epiphora, photophobia, convulsions in the eyelids and buphthalmos (16).

Due to irritation of the cornea, patients with PCG frequently suffer from corneal epithelial edema and haze. The accumulation of aqueous humor leads to disruption in corneal endothelial integrity (17). A markedly thinned iris with reduced iris folds due to reduced stromal thickness and a severe flattening of the anterior limiting layer with a significant positive correlation with increased intraocular pressure (IOP) were reported in patients with PCG $(18,19)$.

Patients with PCG exhibit corneal edema, increased corneal diameter, damaged Haab's striae or an enlarged axial length (20). In newborns, the normal horizontal diameter is 9.5-10.5 $\mathrm{mm}$, while the corneal diameter in children aged 1 is $10-11.5 \mathrm{~mm}$ (21). Any increase in corneal diameter $(>12 \mathrm{~mm})$ in the first year of life should be noticed by pediatricians (22). The pathological features of PCG are as follows: i) Overlap of ciliary body and TM with the iris; ii) thickened trabecular beams in the trabeculum; and iii) absence of Schlemm's canal (SC) (23).

\section{Treatment strategies for PCG}

The common treatments for PCG include surgery and drug therapy. Carbonic anhydrase inhibitor is an important medication in the clinic with an efficiency to reduce the IOP by $\sim 25 \%$ and fewer general side effects compared with $\beta$-receptor blockers (24). But long-term usage may cause serious adverse reactions, including as anorexia, renal acidosis, thirst, fatigue and growth stagnation (25). Furthermore, certain drugs, e.g. pilocarpine, may result in spasm of the ciliary muscle and myopia in pediatric patients (26). At present, the most promising treatment strategy for PCG is surgical intervention combined with drug therapy. However, certain surgical treatments, including filtration surgery, still have disadvantages that may affect the quality of life of patients with PCG. The filtering bleb scar arising from filtration surgery may have an effect on IOP control (27). Furthermore, in certain cases, the visual function damage continues to progress after surgery.

Gene therapy refers to transferring genetic material into individuals with the aim of curing a disease or improving the clinical status of a patient. The major purpose of gene therapy is to replace non-functional or defective genes with new genes that are fully functional so that the gene expression level may revert to its normal state (28). The advances in gene therapy hold significant promise for the treatment of ophthalmic conditions, particularly in PCG. Several studies in animal models have confirmed that gene therapy has efficient effects on aqueous humor and may exert optic ganglion cell protection. Perkins et al (29) indicated that treatment of the fascia fibroblasts in a rabbit model with human p21 gene may inhibit cell proliferation and increase the anti-fibroproliferative ability in glaucoma-filtering surgery. This result was also affirmed by Wen et al (30). Heatley et al (31) transferred human p21 gene into a high-IOP monkey model with recombined adenovirus vector and indicated that the side effect of anti-metabolic drugs (mitomycin C) in filtration surgery had been inhibited. Those pieces of evidence suggest that gene therapy may be suitable for patients with PCG. However, the accurate gene targets, namely the pathogenic genes of $\mathrm{PCG}$, require to be determined.

\section{Recent advances in technologies for PCG-associated gene identification}

To identify disease-associated loci, the Human Genome Organization generated a specific nomenclature for glaucoma-associated genetic loci in 2011 (32). 'GLC' is a general nomenclature for gene loci in glaucoma. The numbers ' 1,2 and 3' refer to the type of primary glaucoma (open-Angle, closed-Angle and congenital/infantile glaucoma, respectively). 'A, B, C and D' indicate the chronology of the mapped genes. Analyses of genetic markers in pedigrees have mapped a glaucoma-associated gene to a region of chromosome 1q, which was termed GLC1A (33). Linkage studies of glaucoma of other pedigrees have mapped PCG-associated genes to chromosome 2p21-22 (GLC3A), 1p36.2-36.1 (GLC3B) and14q24.3 (GLC3C). The technologies available for the study of the genetics of PCG include sequence analysis, targeted gene mutant analysis and deletion/duplication analysis. Technologies for the identification of PCG-associated genes include linkage analysis, 
exome sequencing, whole-exome sequencing and comparative genomic hybridization, which are discussed further below.

Linkage analysis. Linkage analysis is based on familial research and is primarily used for monogenic diseases (34). Linkage analysis was the primary tool used to map the genetics of PCG. The first PCG gene locus, located at 2p21 (GLC3A), was observed in 11 Turkish families with PCG and identified by genetic linkage analysis in 1995 (35). The second chromosomal site to be identified to be associated with PCG is 1p36 (GLC3B), which was identified in eight families with PCG (36). In 2002, a third locus was identified on 14q24 (GLC3C) (37). The likelihood of odds (LOD) score is a basis for the linkage analysis to calculate the logarithm of the likelihood ratio. A LOD score $\geq 3$ is considered to indicate a link. However, patients with $\mathrm{PCG}$ are rare with a large pedigree; thus, the utility of LOD scores may be limited.

Exome sequencing. Exome sequencing is a technique for identifying mutations in known disease-associated genes through PCR amplification, sequencing and sequence alignment (38). It is used to capture DNA in the exome region and determine the existence of base variations (39). Sheikh et al (40) identified two novel mutations, a missense mutation (c.107G $>$ A) and a 12-bp deletion mutation (c.198-209delGGGCCAGGCGGC) in the CYP1Bl gene in a Pakistani family with PCG using exon sequencing. In 2015, Micheal et al (41) identified four homozygous CYP1B1 mutants (p.Ala288Pro, p.Asp242Ala, p.Arg355* and p.Arg290Profs*37) in 39 families with PCG using exome sequencing.

Whole-exome sequencing. Whole-exome sequencing is a high-throughput genome analysis method based on exon sequencing. Whole-exome sequencing is currently used for the identification of pathogenic genes and mutated sites in various diseases, including digestive tract tumors and melanoma, mental retardation, primitive dwarfism and idiopathic pulmonary hypertension (42). Due to its high efficiency, this method is applied in prenatal diagnosis, particularly for researching rare mutations in small families and sporadic cases. In 2012, Lim et al (43) screened 17 CYP1B1 variations in 57 patients with PCG in the US using whole-exome sequencing.

Comparative genomic hybridization ( $C G H)$. $\mathrm{CGH}$ is a genomic analysis technology used for the detection of copy number variations (CNVs), which serves an important role in human evolution, genetic diversity and disease susceptibility (44). In 2011, Akarsu et al (45) analyzed 25 CNVs (5 deletions and 20 duplications) in 12 Korean patients with PCG using $\mathrm{CGH}$ and indicated that the incidence of rare gene-containing $\mathrm{CNV}$ frequencies in patients with $\mathrm{PCG}$ was 5-30\%. Abu-Amero et al (46) identified two 7p heterozygous duplications and a $4 \mathrm{p}$ homozygous microdeletion in a female Saudi Arabian patient with CYP1B1-negative PCG. In addition to gene copy numbers, studies have indicated that chromosomal aberrations are another possible cause of PCG. Broughton et al (47) reported on the pericentric inversion of chromosome 11 in a pedigree affected by PCG and bilateral corneal disease. Nakane et al (48) described that a 6p subtelomere deletion occurred in a patient with $\mathrm{PCG}$, severe mental retardation and growth impairment. Merritt and Lindor (49) detected a duplication on $7 \mathrm{q} 11.23$ with $\mathrm{CGH}$ in a family suffering from PCG. As the lowest limit of DNA fragment analysis is 3-5 $\mathrm{Mb}$ for $\mathrm{CGH}$, if the DNA amplification level is extremely low or a small DNA fragment is lost, this method is not able to detect it due to a lack of sensitivity.

\section{Genetic aspects and mutations in genes associated with PCG}

A high level of heterogeneity has been noted in the disease-associated loci in patients with PCG, penetrance defects and prevalence of the disease among different populations. PCG is an autosomal recessive disease with variable penetrance $(50,51)$. In 1970, Rasmussen and Philip (52) reviewed the literature on the heredity aspects of congenital glaucoma and indicated that PCG exhibited bilateral heredity in monozygotic male twins; this and was later confirmed by Fried et al (53). Genetic analysis of the families of patients with PCG suggested that the incidence in monozygotic male twins was higher compared with that in dizygotic twins (54). Therefore, it has been proposed that the inheritance of PCG includes an autosomal-recessive and sex-associated element with variable penetrance. In general, three PCG genetic loci have been implicated in different geographic locations worldwide. Although the exact pathogenic gene and pathway have remained to be confirmed, several implicated genes, including CYP1B1, appear to participate in anterior segment development and they may be involved in the development of PCG (Table I). The CYP1B1 gene is the most studied gene with over 150 variants in PCG. Furthermore, certain evidence provided that the angiopoietin 1 (ANGTP)/TEK receptor tyrosine kinase (TEK) pathway may take part in the pathogenesis of PCG.

CYP1B1 gene. CYP1B1 (previously known as glaucoma 3 , primary infantile) encodes a homonymous protein (cytochrome P450, family 1, subfamily B and polypeptide 1), and is composed of 3 exons (3, 711,044 and 3,707 bp in length) and two introns (390 and 3,032 bp in length) (Fig. 1) (55). The protein is a member of the B subfamily of cytochrome P450 1, which catalyzes the NADPH-dependent mono-oxygenation of xenobiotics and endogenous molecules (56). The CYP1B1 gene is expressed in various tissue types in the human body, including in the cornea, ciliary body, iris and retina, and may participate in the development of TM (57). CYP1B1 is also expressed in early embryos in several species during the development of ocular tissues (58). CYP1B1 gene mutations may impair the enzymatic activity and stability and reduce localization of the protein to the mitochondria $(59,60)$. CYP1B1 expression is regulated by aromatic hydrocarbons, adrenocorticotropin and peptide hormones (61).

The spectrum of CYP1B1 mutations varies widely across different populations (62). Pathogenic CYP1B1 alleles have been identified in $20 \%$ of PCG cases in Japanese patients and $14.9 \%$ of patients from the US. Similarly, the rate of CYP1B1-mutated alleles is $\sim 15.2 \%$ in Chinese patients with PCG, considerably lower than the percentage in patients from Morocco (47.7\%) (63) and Saudi Arabia (75.9\%) with mutated CYP1B1 alleles (46). Biallelic variants of CYP1B1 are well known as the genetic cause of PCG, accounting for $22 \%$ in Australian patients with PCG (64). 
Table I. Genetic loci and genes associated with the pathogenesis of PCG.

\begin{tabular}{|c|c|c|c|c|}
\hline Locus & Chromosomal region & Gene & Functions & Pathway implicated in PCG \\
\hline GLC3A & $2 \mathrm{p} 21-22$ & CYP1B1 & Endogenous steroid metabolism & Retinoic acid-independent pathway \\
\hline GLC3B & $1 \mathrm{p} 36.2-36.1$ & Unknown & Unknown & Unknown \\
\hline GLC3C & $14 q 24.3$ & LTBP2 & $\begin{array}{l}\text { Extracellular matrix organization } \\
\text { and formation }\end{array}$ & BMP/TGF- $\beta$ pathway ${ }^{a}$ \\
\hline Undesignated & $\operatorname{lq} 24.3-\mathrm{q} 25.2$ & MYOC & $\begin{array}{l}\text { Trabecular meshwork inducible } \\
\text { glucocorticoid response protein; } \\
\text { compound variations with CYP1B1 }\end{array}$ & $\begin{array}{l}\text { IL-1/NF- } \mathrm{B} \text { inflammatory stress } \\
\text { responsea }\end{array}$ \\
\hline Undesignated & $17 q 21.33$ & COL1A1 & $\begin{array}{l}\text { A core component of the } \\
\text { extracellular matrix in ocular } \\
\text { tissues, such as TM and SC }\end{array}$ & Unknown \\
\hline Undesignated & $6 \mathrm{p} 25.3$ & FOXC1 & Development of anterior segment & Unknown \\
\hline Undesignated & $8 q 23.1$ & ANGTP1 & $\begin{array}{l}\text { Effects on pro-angiogenic and } \\
\text { vascular stabilizing through } \\
\text { activation of TEK }\end{array}$ & ANGTP/TEK signaling pathway \\
\hline Undesignated & $9 \mathrm{p} 21.2$ & TEK & Formation and homeostasis of SC & \\
\hline
\end{tabular}

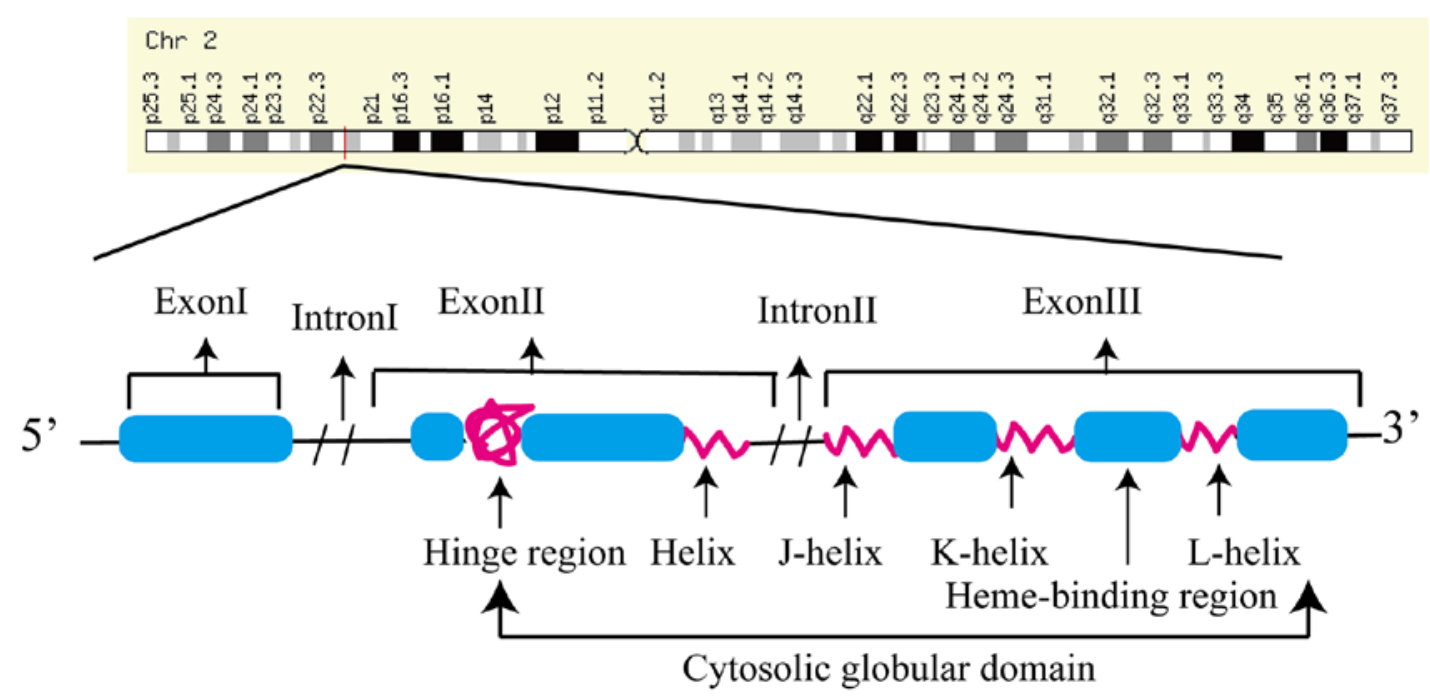

Figure 1. Schematic representation of the CYP1B1 gene. In humans, the CYP1B1 gene, which is composed of three exons and two introns, is mapped on chromosomal location 2p21-22. The coding region of the CYP1B1 gene ranges from the 5 ' end of the 2nd exon to the last exon. A set of conserved core structures for the heme-binding region corresponds to the carboxy-terminal region of the cytochrome P450 enzyme. Chr, chromosome; CYP1B1, cytochrome P450 family 1 subfamily B member 1 .

Libby et al (65) demonstrated that developmental defects of TM and SC in eye tissue sections of CYP1B1-knockout mice were similar to those in patients with PCG. Several studies reported that the IOP was increased in CYP1B1-knockout mice (66-68), thus indicating increased oxidative stress levels along with insufficient formation of the periosteum, similar to the alterations observed in human glaucomatous TM tissues. These changes may result in ultrastructural irregular collagen distribution in TM tissue. In Spanish patients with PCG, $\sim 30 \%$ of cases carry loss-of-function CYP1B1 variants, which normally results in a null genotype (69).

Alsaif et al (70) identified that c.1405C $>\mathrm{T}$ (p.R469W) exhibited a penetrance of $93 \%$ in patients with PCG, particularly in Saudi Arabia, followed by a c.182G>A (p.G61E) mutation with $87.7 \%$ penetrance. Li et al (71) summarized that the primary mutation sites in CYP1B1 gene mutational spectra associated with PCG were G61E, R368H/L, R390H, E387K and R469W, while L385F, R390H and L107V were the most commonly observed sites in China. Ou et al (72) indicated that 
L107V and R390H were common CYP1B1 mutations with allele frequencies of 3.19 and $3.09 \%$, respectively, in Chinese patients with PCG. Therefore, L107V and R390H may be the most relevant pathogenic mutations in Chinese patients with PCG.

Among the known loci, two variants, which had not been previously associated with PCG, were identified in Brazilian patients (c.182G $>$ A, c.241T $>$ A) (73). Rashid et al (74) identified three novel (c.542T $>\mathrm{A}, \mathrm{c} .1436 \mathrm{~A}>\mathrm{G}$ and c.1325delC) and five known (c.868dupC, c.1168C $>$ T, c. $1169 \mathrm{G}>\mathrm{A}$, c.1209insTCATGCCACC and c.1310C $>$ T) variants of CYP1B1 in 14 Pakistani families. Furthermore, 5 different CYP1B1 variants in 7 families were investigated, indicating that the patients with missense mutations (c.1169G $>$ A and c.1311G $>$ A) had severe phenotypes and poor vision following surgical intervention compared to patients with null variants (75). Talebi et al (76) recruited an Iranian family with PCG and discovered three novel CYP1B1 mutations (c.G701>A, c.707delG and c.710delA). These mutations expanded the database of known CYP1B1 gene mutations associated with PCG, which may be useful for genetic counseling and prenatal diagnosis for affected families.

Although >150 CYP1B1 variants have been reported in PCG cases worldwide, they only explain $87 \%$ of cases in inbred populations and $25-27 \%$ of cases in heterogeneous ethnicities (77).

MYOC gene. MYOC is located on chromosome lq24.3-q25.2 and contains three exons (604, 126 and 782 bp in length). MYOC encodes myocilin, which is composed of 504 amino acids (78). MYOC is expressed in numerous different types of eye tissue, including TM, sclera, ciliary body and retina. The majority of mutations of this gene identified are located in the third exon and mutations of the MYOC gene may result in structural changes in TM and the ciliary body, impeding the flow of aqueous humor and increasing IOP (78).

Nazir et al (79) performed genotyping for rs74315341 and rs879255525 in MYOC in a cohort of 100 patients with glaucoma and 100 control subjects. They demonstrated that the single nucleotide polymorphisms rs74315341 and rs879255525 in MYOC were associated with glaucoma. Millá et al (80) identified a novel variation (p.Glu352Lys) of MYOC in 207 Canadian patients with glaucoma; however, its pathogenicity remains to be determined. Recent studies on the MYOC gene are primarily focused on primary open-angle glaucoma. A study in a Chinese pedigree with primary open-angle glaucoma spanning four generations identified a novel mutation (c.1309T>C, p.Y437H) in the MYOC gene (81). Kaur et al (82) detected a compound mutation (CYP1B1: c.G1103A, Ar9368His; MYOC: c.G114T, p.Gln48His) with a detection rate of $1.4 \%$ (1/72) in PCG. A Gln48His mutation of MYOC was observed in 5 patients with PCG in India (83), and Kim et al (84) identified two novel MYOC mutants (c.L228S and p.E240G) in two Korean patients with PCG (detection rate of $2.4 \%, 2 / 85$ ) using a bi-directional sequencing method. Chen et al (85) hypothesized that MYOC gene mutants may act in association with CYP1B1 through compound variants in patients with $\mathrm{PCG}$, while the mechanism remains to be determined. Although the detection rates of MYOC mutations are lower than CYP1B1 mutations, they may still explain the pathogenic causes in a proportion of PCG cases.

FOXC1 gene. FOXC1 encodes forkhead box protein $\mathrm{C} 1$, which is composed of 553 amino acids. FOXC1 is expressed in the cornea, TM and optic nerve. FOXC1 is present in mesodermal and neural crest-derived cells, including cells of the anterior segment of the eye, and it regulates the external flow and IOP of the aqueous humor. Siggs et al (86) noticed that patients with PCG and FOXC1 variants were frequently complicated with systemic features associated with Axenfeld-Rieger syndrome, including hearing loss, heart murmur and developmental delay. Smith et al (87) observed abnormal development of the anterior segment (including Schlemm's canal, TM and iris) in mice with a FOXC1 gene mutation and these abnormalities were similar to the phenotypes observed in anterior ocular dysplasia in patients with PCG. Amongst 210 patients with PCG, two heterozygous missense mutations (H128R and $\mathrm{C} 135 \mathrm{Y}$ ) and three code shift mutations (g.1086delC, g.1155de19 bp and g.1947dup25 bp) were observed in FOXC1 in 5 subjects $(2.38 \%)$ (88). Medina-Trillo et al (89) analyzed FOXC1 variants (rs77888940, c.-429C>G; rs730882054, c.1134_144delCGGCGGCGCGG; rs35717904, c.*734A>T; rs185790394, c.-244C>T; rs79691946, c.*454C>T) in 133 pedigrees with PCG and demonstrated that FOXC1 mutations may affect the formation of goniodysgenesis in PCG. These results suggest that FOXC1 may be associated with the pathogenesis of PCG.

COL1A1 gene. COL1A1 is located on chromosome 17q21.33 and encodes the pro- $\alpha 1$ chains of type I collagen, whose triple helix comprises two $\alpha 1$ chains and one $\alpha 2$ chain. Mutations in the COL1A1 gene are typically associated with skeletal and dermatological conditions, including Ehlers-Danlos syndrome, bone mineral density variation, osteoporosis and Caffey disease (90). Mauri et al (91) identified compound heterozygous variants of COL1A1 (p.Met264Leu; p.Ala1083Thr) in 26 patients with PCG by whole-exome sequencing. Collagen protein is a core component of the extracellular matrix (ECM) of the TM, SC and lamina cribrosa, all of which are ocular tissues involved in the development of glaucoma. In addition, pedigree studies have indicated that variants of COL1A1 may affect the development of central corneal thickness and thus result in PCG $(92,93)$.

Latent transforming growth factor $(T G F)$ - $\beta$ binding protein 2 (LTBP2) gene. LTBP2 is mapped to $14 \mathrm{q} 24.3$, located $\sim 1.3 \mathrm{Mb}$ from the GLC3C locus (14q24) (94). The LTBP2 gene consists of 36 exons (95). LTBP2 is expressed in elastic tissues and was determined to be a PCG-associated gene by Narooie-Nejad et al (96) and Ali et al (97) in 2009. Subsequently, LTBP2 was demonstrated to be localized to the anterior segment and ciliary body. LTBP 2 may be associated with PCG due to its putative effect on TGF- $\beta$ signaling and the ECM of TM. The study of mutations of the LTBP2 gene in patients with PCG thus came into focus. A homozygous variant of LTBP2 (c.895C>T, p.R299X) was identified in two Marfan-like phenotype Roma patients (98). Patients with Marfan syndrome frequently present with lens luxation with a high IOP, which may develop into glaucoma (99). Yang et al (100) identified 
a nonsense mutation (c.2421G $>$ A, p.W807X) in LTBP2 in 8 Indian patients with PCG. Shazia et al (101) identified two mutations in the LTBP2 gene (c.4934G>A, p.Arg1645Glu; c.4031_4032insA, p.Asp1345Glyfs*6) in two Pakistani families with PCG. Kuehn et al (102) observed certain symptoms, including increased IOP, globe enlargement of the eye and elongated ciliary body in 8 -week-old cats, which had a 4 base-pair insertion in exon 8 of the LTBP2 gene. Inoue et al (103) illustrated that the LTBP2 mutants had an abnormal domain structure, which may have resulted in the arrest of secretion of this protein, a process which is essential for the formation of microfibril bundles in ciliary zonules. Consequently, mutations of LTBP2 are a plausible cause of congenital ocular structural abnormalities that may result in PCG; however, the underlying mechanisms by which these mutations lead to PCG remain to be determined.

ANGPT1/TEK: Vascular development in PCG. The ANGPT1 gene is located on 8q23.1 and encodes ANGPT1. ANGPT1 is a secreted glycoprotein, which activates receptors by inducing tyrosine phosphorylation. It serves an essential role in blood vessel maturation and is also involved in the development of SC. Developmental disorders in aqueous humor drainage in the SC and TM were frequently observed in patients with PCG with increased IOP $(104,105)$. The ANGPT/TEK pathway was demonstrated to be involved in the development of SC and aqueous outflow $(106,107)$.

The ANGPT/TEK signaling pathway is composed of 3 ligands (ANGPT1, ANGPT2 and ANGPT4) and its receptor TEK (108). TEK (also known as TIE2) is a receptor tyrosine kinase encoded by the TIE2 gene, which is expressed in endothelial cells. Defects in TEK may result in vascular malformations (109). In human eyes, expression of the TEK receptor is notably high in the SC endothelium. ANGPT1 is a vascular growth factor which affects endothelial activation and dysfunction (110) ANGPT1 is the primary ligand of TEK in the iridocorneal angle and is additionally expressed in certain other vascular-supporting cells (111). The ANGPT1 gene exerts its pro-angiogenic and vascular-stabilizing effects through the activation of TEK. ANGPT2, another ligand of TEK, is a cellular context-dependent agonist/antagonist of ANGPT/TEK signaling. ANGPT2 compensates for the loss of ANGPT1 in ANGPT/TEK signaling (112). The third ligand of TEK is ANGPT4, which is a poorly characterized ligand in mouse models (113). ANGTP4 is important for retinal fluid clearance (114).

Commonly, aqueous humor flow produced by the ciliary body is exhausted through TM and SC, which lie on the iridocorneal angle of the eye. Under normal circumstances, when TEK combines with ANGPT1, it may activate signals, and subsequently, the endothelial cells on the inner wall of SC are under the pressure generated by aqueous humor flow and the gradients. As a result, vacuoles form on endothelial cells, while the pressure-dependent outer pouches of endothelial cells create a channel for aqueous humor flow to cross the SC. The ANGPT/TEK pathway preserves the stability of SC and TM functions (Fig. 2). Its inactivation leads to degeneration of TM and SC, which may further develop into irregular canal formation, increased IOP and glaucoma.

Thomson et al (115) demonstrated that genetic disruption in the ANGPT/TEK signaling pathway may result in increased IOP, buphthalmos and possibly even retinal ganglion degeneration. Subsequently, Thomson et al (116) determined that loss-of-function of the ANGPT/TEK signaling pathway resulted in severely hypomorphic canals with elevated IOP in humans and in ANGPT-knockout mice. They identified 3 mutations (p.Q236*, p.R494* and p.K249R) of ANGPT1 among 284 patients with PCG. Souma et al (117) described 10 heterozygous mutations of TEK in 189 pedigrees with PCG. These results suggested that the ANGPT/TEK signaling pathway may be implicated in the development of PCG. Therefore, numerous genes associated with the ANGPT/TEK signaling pathway may be involved in the development of PCG.

\section{Conclusions}

PCG is a complex ocular disorder associated with considerable clinical and genetic heterogeneity. It is a type of serious glaucoma, which primarily affects children of consanguineous couples. Although sporadic cases of PCG may occur, the relevant clinical data and genetic studies provide strong evidence to illustrate that PCG is an autosomal recessive disease. At times, PCG may also be accompanied by other rare genetic diseases, including hypoplasia corpus callosum. Genetic abnormalities may be suspected in pediatric patients with PCG and it may be recommended to exclude the presence of other genetic syndromes such as Axenfeld-Rieger syndrome. The pathogenesis and therapy of PCG are a focal point of research regarding this disease. To date, genetic studies have identified several PCG-associated genes and enlarged the gene map of PCG. However, the associated genes and mechanisms underlying the development of PCG have remained to be fully identified.

Patients with PCG are predominantly from small families, which causes difficulties in studying the genetics of this disease. Developed techniques, including molecular genetics technology and applications of whole-exome sequencing and next-generation sequencing (NGS), have a unique value for the study of cases of PCG, particularly in small families. The elucidation of the pathogenesis of PCG may be assisted by the exploration of novel pathogenic genes, identification of mutations and understanding of the functional relevance of these genes and mutations. The 'third generation of high-throughput NGS technology' or single-molecule real-time sequencing has the advantage of being able to analyze short read lengths. With developments in sequencing technology, it may be possible to perform quantitative analyses of full-length genes on an entire transcriptome level in patients with PCG.

Studies on known PCG-associated genes, including CYP1B1, LTBP2, FOXC1 and MYOC and the ANGPT/TEK pathway, may form a basis for potential gene therapies. It is worthwhile to elucidate the association between CYP1B1, LTBP2, FOXC1 and MYOC and the ANGPT/TEK pathway. The genes reported so far do not fully explain the pathogenesis of PCG, and thus, other genes may also be associated with the development of PCG. Further studies are required to fully understand the complex association between the genotype and phenotype of patients with PCG. The use of transgenic and gene knockout animal models may be necessary to study the function of the PCG-associated genes and mutations 


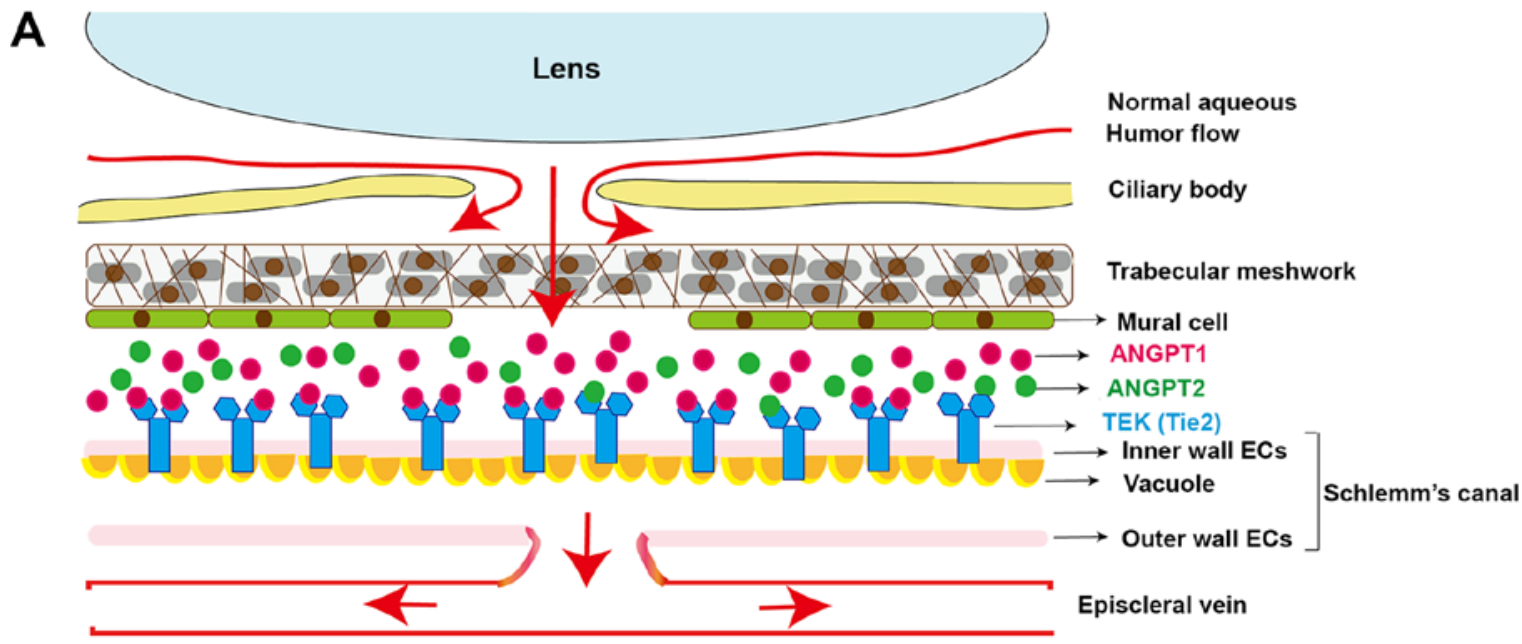

B

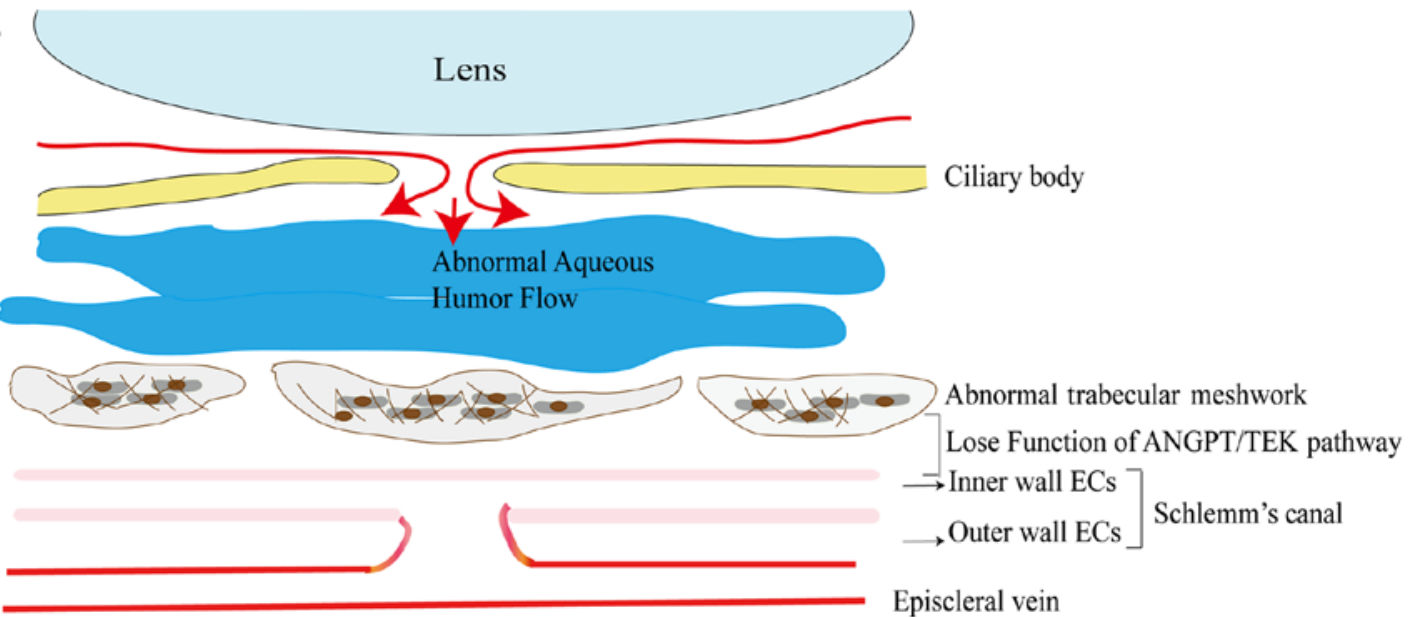

Figure 2. The role of the ANGPT/TEK pathway in SC and TM. (A) Normally, the aqueous humor is drained via the TM and SC-ECs, along with the formation of giant vacuoles. TEK combines with ANGTP1 primarily, while it has limited compensation from ANGPT2. ANGPT/TEK signaling is important for maintaining the integrity and function of SC and thus ensures that the aqueous humor flows out fluently. (B) Absence of continuous ANGTP/TEK signaling results in an increase of EC apoptosis, as well as a decrease of the formation of giant vacuoles and a reduction of the aqueous humor flow going through SC. The accumulated aqueous humor leads to degeneration of the TM and limitation of SC development. TEK, TEK receptor tyrosine kinase; ANGTP1, angiopoietin 1; TM, trabecular meshwork; SC, Schlemm's canal; ECs, endothelial cells.

in vivo and in vitro, and elucidate the molecular mechanisms underlying the development of PCG.

Compared with the traditional treatments, gene therapy as a novel therapeutic method has been gradually applied in the field of medicine, providing a broad prospect for the prevention and treatment of PCG. However, it has limitations regarding gene targets, which are used in the treatment of PCG. The potential gene targets used in PCG therapy must to satisfy the following conditions: i) Genes with mutations associated with PCG, ii) gene expression is altered under primary congenital glaucomatous conditions, iii) genes that are known to be involved in pathways recognized as having an effect on IOP or aqueous humor outflow. Gene therapy for PCG is promising but still in the initial stage of experimentation in the field of ophthalmology. Bioinformatics databases and functional genomics may contribute to improved counseling and treatment strategies for patients with PCG.

\section{Acknowledgements}

Not applicable.

\section{Funding}

The current study was supported by grants from the National Natural Science Foundation of China (grant no. 81470667), the Department of Science and Technology of Sichuan Province (grant no. 20ZDYE1478), the Health Commission of Sichuan Province (grant no. 17ZD024) and the Sichuan Academy Medical Science \& Sichuan Provincial People Hospital (grant no. 2018LY01) and Science \& Technology Bureau of Chengdu (grant no. 2019- YF05-00198-SN.

\section{Availability of data and materials}

Not applicable.

\section{Authors' contributions}

CL reviewed literature and wrote the manuscript. DZ designed and revised the manuscript. CL, JZ, HS, QD and XL collected related articles. DZ gave final approval for publication. All authors read and approved the final manuscript. 


\section{Ethics approval and consent to participate}

Not applicable.

\section{Patient consent for publication}

Not applicable.

\section{Competing interests}

The authors declare that they have no competing interests.

\section{References}

1. Cook C and Foster P: Epidemiology of glaucoma: What's new? Can J Ophthalmol 47: 223-226, 2012.

2. Wang YX, Xu L, Yang H and Jonas JB: Prevalence of glaucoma in North China: The Beijing Eye Study. Am J Ophthalmol 150: 917-924, 2010.

3. Gomes HA, Moreira BS, Sampaio RF, Furtado SRC, Cronemberger S, Gomes RA and Kirkwood RN: Gait parameters, functional mobility and fall risk in individuals with early to moderate primary open angle glaucoma: A cross-sectional study. Braz J Phys Ther 22: 376-382, 2018.

4. Durnian JM, Cheeseman R, Kumar A, Raja V, Newman W and Chandna A: Childhood sight impairment: A 10 -year picture. Eye (Lond) 24: 112-117, 2010.

5. Moschos MM, Nitoda E, Fenzel I, Song X, Langenbucher A, Kaesmann B, Seitz B and Gatzioufas Z: Prognostic factors of pediatric glaucoma: A retrospective study. Int Ophthalmol 39: 359-373, 2019.

6. Sharafieh R AHC MS: Molecular genetics of primary congenital glaucoma. Genet Dis Eye Chapter 17: 295-307, 2011.

7. Hoguet A, Grajewski A, Hodapp E and Chang TC: A retrospective survey of childhood glaucoma prevalence according to Childhood Glaucoma Research Network classification. Indian J Ophthalmol 64: 118-123, 2016.

8. Pedersen KB, Kappelgaard P, Kessel L, Sandfeld L, Zibrandtsen N and Bach-Holm D: Primary congenital glaucoma in Denmark, 1977-2016. Acta Ophthalmol 98: 182-189, 2020.

9. Gothwal VK, Bharani S and Mandal AK: Impact of surgery on the quality of life of caregivers of children with congenital glaucoma. Ophthalmology 123: 1161-1162, 2016.

10. MacKinnon JR, Giubilato A, Elder JE, Craig JE and Mackey DA Primary infantile glaucoma in an Australian population. Clin Exp Ophthalmol 32: 14-18, 2004.

11. Gilbert $\mathrm{C}$ and Foster A: Childhood blindness in the context of VISION 2020-the right to sight. Bull World Health Organ 79: 227-232, 2001.

12. Tamcelik N, Atalay E, Bolukbasi S, Capar O and Ozkok A: Demographic features of subjects with congenital glaucoma. Indian J Ophthalmol 62: 565-569, 2014.

13. Abouelhoda M, Sobahy T, El-Kalioby M, Patel N, Shamseldin H, Monies D, Al-Tassan N, Ramzan K, Imtiaz F, Shaheen R and Alkuraya FS: Clinical genomics can facilitate countrywide estimation of autosomal recessive disease burden. Genet Med 18: 1244-1249, 2016

14. Ho CL and Walton DS: Primary congenital glaucoma: 2004 update J Pediatr Ophthalmol Strabismus 41: 271-288; quiz 300-271, 2004.

15. Pilat AV, Shah S, Sheth V, Purohit R, Proudlock FA, Abbott J and Gottlob I: Detection and characterisation of optic nerve and retinal changes in primary congenital glaucoma using hand-held optical coherence tomography. BMJ Open Ophthalmol 4: e000194, 2019.

16. Chang TC, Grajewski AL and Cavuoto KM: Evolving perspectives on congenital glaucoma. Curr Ophthalmol Rep 3: 85-90, 2015.

17. Amini H, Fakhraie G, Abolmaali S, Amini N and Daneshvar R: Central corneal thickness in Iranian congenital glaucoma patients. Middle East Afr J Ophthalmol 19: 194-198, 2012.

18. Pilat AV, Proudlock FA, Shah S, Sheth V, Purohit R, Abbot J and Gottlob I: Assessment of the anterior segment of patients with primary congenital glaucoma using handheld optical coherence tomography. Eye (Lond) 33: 1232-1239, 2019.

19. Lopes JE, Wilson RR, Alvim HS, Shields CL, Shields JA, Calhoun J, Fontanarosa J and Steinmann WC: Central corneal thickness in pediatric glaucoma. J Pediatr Ophthalmol Strabismus 44: 112-117, 2007.
20. Jin SW and Ryu WY: Clinical manifestations of strabismus in patients with primary congenital glaucoma. Semin Ophthalmol 34: 451-457, 2019.

21. Arthur E, Elsner AE, Sapoznik KA, Papay JA, Muller MS and Burns SA: Distances from capillaries to arterioles or venules measured using OCTA and AOSLO. Invest Ophthalmol Vis Sci 60: 1833-1844, 2019

22. Patil B, Tandon R, Sharma N, Verma M, Upadhyay AD, Gupta V and Sihota R: Corneal changes in childhood glaucoma. Ophthalmology 122: 87-92, 2015.

23. Shohdy KS, Rashad WA, Fargoun MK and Urban P: The morphogen behind primary congenital glaucoma and the dream of targeting. Rom J Morphol Embryol 58: 351-361, 2017.

24. Sigle KJ, Camano-Garcia G, Carriquiry AL, Betts DM, Kuehn MH and McLellan GJ: The effect of dorzolamide 2\% on circadian intraocular pressure in cats with primary congenital glaucoma. Vet Ophthalmol 14 (Suppl 1): S48-S53, 2011.

25. Angeli A, Abdel-Aziz AA, Nocentini A, El-Azab AS, Gratteri P and Supuran CT: Synthesis and carbonic anhydrase inhibition of polycyclic imides incorporating N-benzenesulfonamide moieties. Bioorg Med Chem 25: 5373-5379, 2017.

26. Costa CM, Louvisse de Abreu LC, dos Santos EP, Franca Presgrave OA, Rocha Pierucci AP, Rodrigues CR, de Sousa VP, Nicoli S, Ricci Junior E and Cabral LM: Preparation and evaluation of chitosan submicroparticles containing pilocarpine for glaucoma therapy. Curr Drug Deliv 12: 491-503, 2015.

27. Morales J, Al Shahwan S, Al Odhayb S, Al Jadaan I and Edward DP: Current surgical options for the management of pediatric glaucoma. J Ophthalmol 2013: 763735, 2013.

28. Al-Saikhan FI: The gene therapy revolution in ophthalmology. Saudi J Ophthalmol 27: 107-111, 2013.

29. Perkins TW, Faha B, Ni M, Kiland JA, Poulsen GL, Antelman D, Atencio I, Shinoda J, Sinha D, Brumback L, et al: Adenovirus-mediated gene therapy using human p21WAF-1/Cip-1to prevent wound healing in a rabbit model of glaucoma filtration surgery. Arch Ophthalmol 120: 941-949, 2002.

30. Wen SF, Chen Z, Nery J and Faha B: Characterization of adenovirus p21 gene transfer, biodistribution, and immune response after local ocular delivery in New Zealand white rabbits. Exp Eye Res 77: 0-365.2003

31. Heatley G, Kiland J, Faha B, Seeman J, Schlamp CL, Dawson DG, Gleiser J, Maneval D, Kaufman PL and Nickells RW: Gene therapy using p21WAF-1/Cip-1 to modulate wound healing after glaucoma trabeculectomy surgery in a primate model of ocular hypertension. Gene Ther 11: 949-955, 2004.

32. Khan AO: Genetics of primary glaucoma. Curr Opin Ophthalmol 22: 347-355, 2011.

33. Sheffield VC, Stone EM, Alward WL, Drack AV, Johnson AT, Streb LM and Nichols BE: Genetic linkage of familial open angle glaucoma to chromosome 1q21-q31. Nat Genet 4: 47-50, 1993.

34. Talluri R and Shete S: A linkage disequilibrium-based approach to selecting disease-associated rare variants. PLoS One 8: e69226, 2013.

35. Sarfarazi M, Akarsu NA, Hossain A, Turacli ME, Aktan SG, Barsoum-Homsy M. Chevrette L and Sayli BS: Assignment of a locus (GLC3A) for primary congenital glaucoma (Buphthalmos) to 2p21 and evidence for genetic heterogeneity. Genomics 30: 171-177, 1995.

36. Akarsu AN, Turacli ME, Aktan SG, Barsoum-Homsy M, Chevrette L, Sayli BS and Sarfarazi M: A second locus (GLC3B) for primary congenital glaucoma (Buphthalmos) maps to the 1p36 region. Hum Mol Genet 5: 1199-1203, 1996.

37. Stoilov IR and Sarfarazi M: The third genetic locus (GLC3C) for primary congenital glaucoma (PCG) maps to chromosome 14q24.3. Invest Ophth Vis Sci 43: 847-847, 2002.

38. Tian Q, Li FH, Zhao KX, Wang L, Shan XY, Pang YY, Li YX, Wu MJ, Qiu F and Li HY: A novel mutation in the myocilin gene identified in a Chinese primary open angle glaucoma family. Zhonghua Yi Xue Yi Chuan Xue Za Zhi 24: 629-634, 2007 (In Chinese).

39. Chen R, Gong B, Li Q, Zeng G, Hao F, Li N, Shi Y and Zhang D: Analysis of COL9A2 gene mutations in a Chinese Han population with pathological myopia. Zhonghua Yi Xue Yi Chuan Xue Za Zhi 31: 129-133, 2014 (In Chinese).

40. Sheikh SA, Waryah AM, Narsani AK, Shaikh H, Gilal IA, Shah K, Qasim M, Memon AI, Kewalramani P and Shaikh N: Mutational spectrum of the CyP1B1 gene in Pakistani patients with primary congenital glaucoma: Novei variants and genotype-phenotype correlations. Mol Vis 20: 991-1001, 2014.

41. Micheal S, Ayub H, Zafar SN, Bakker B, Ali M, Akhtar F, Islam F, Khan MI, Qamar R and den Hollander AI: Identification of novel CYP1B1 gene mutations in patients with primary congenital and primary open-angle glaucoma. Clin Exp Ophthalmol 43: 31-39, 2015. 
42. Koparir A, Karatas OF, Yuceturk B, Yuksel B, Bayrak AO Gerdan OF, Sagiroglu MS, Gezdirici A, Kirimtay K, Selcuk E, et al Novel POC1A mutation in primordial dwarfism reveals new insights for centriole biogenesis. Hum Mol Genet 24: 5378-5387, 2015.

43. Lim SH, Tran-Viet KN, Yanovitch TL, Freedman SF, Klemm T, Call W, Powell C, Ravichandran A, Metlapally R, Nading EB, et al: CYP1B1, MYOC, and LTBP2 mutations in primary congenital glaucoma patients in the United States. Am J Ophthalmol 155: 508-517, 2013.

44. Zhang C, Cerveira E, Romanovitch M and Zhu Q: Array-based comparative genomic hybridization $(\mathrm{aCGH})$. Methods Mol Biol 1541: 167-179, 2017.

45. LeeJH,Ki CS,Kim HJ, Suh W,LeeST,Kim JW and Kee C: Analysis of copy number variation using whole genome exon-focused array CGH in Korean patients with primary congenital glaucoma. Mol Vis 17: 3583-3590, 2011

46. Abu-Amero KK, Osman EA, Mousa A, Wheeler J, Whigham B, Allingham RR, Hauser MA and Al-Obeidan SA: Screening of CYP1B1 and LTBP2 genes in Saudi families with primary congenital glaucoma: Genotype-phenotype correlation. Mol Vis 17: 2911-2919, 2011.

47. Broughton WL, Rosenbaum KN and Beauchamp GR: Congenital glaucoma and other ocular abnormalities associated with pericentric inversion of chromosome 11. Arch Ophthalmol 101: 594-597, 1983.

48. Nakane T, Kousuke N, Sonoko H, Yuko K, Sato H, Kubota T and Sugita K: 6p subtelomere deletion with congenital glaucoma, severe mental retardation, and growth impairment. Pediatr Int 55 376-381, 2013.

49. Merritt JL and Lindor NM: Further clinical description of duplication of Williams-Beuren region presenting with congenital glaucoma and brachycephaly. American J Med Genet Part A 146A: 1055-1058, 2008

50. Suri F, Yazdani S, Narooie-Nejhad M, Zargar SJ, Paylakhi SH Zeinali S, Pakravan M and Elahi E: Variable expressivity and high penetrance of CYP1B1 mutations associated with primary congenital glaucoma. Ophthalmology 116: 2101-2109, 2009.

51. Abu-Amero KK, Kondkar AA and Khan AO: Molecular karyotyping of a dysmorphic girl from Saudi Arabia with CYP1B1-negative primary congenital glaucoma. Ophthalmic Genet 37: 98-101, 2016.

52. Rasmussen DH and Ellis PP: Congenital glaucoma in identical twins. Arch Ophthalmol 84: 827-830, 1970.

53. Fried K, Sachs R and Krakowsky D: Congenital glaucoma in only one of identical twins. Ophthalmologica 174: 185-187, 1977.

54. Walton DS, Nagao K, Yeung HH and Kane SA: Late-recognized primary congenital glaucoma. J Pediatr Ophthalmol Strabismus 50: 234-238, 2013

55. Faiq MA, Dada R, Qadri R and Dada T: CYP1B1-mediated pathobiology of primary congenital glaucoma. J Curr Glaucoma Pract 9 : $77-80,2015$

56. Souzeau E, Dubowsky A, Ruddle JB and Craig JE: Primary congenital glaucoma due to paternal uniparental isodisomy of chromosome 2 and CYP1B1 deletion. Mol Genet Genomic Med 7 : 774, 2019.

57. ManaliD,Craig M,BejjaniBA andEdward DP: Immunolocalization of CYP1B1 in normal, human, fetal and adult eyes. Exp Eye Res 82: 24-32, 2006.

58. Song N, Leng L, Yang XJ, Zhang YQ, Tang C, Chen WS, Zhu W and Yang X: Compound heterozygous mutations in CYP1B1 gene leads to severe primary congenital glaucoma phenotype. Int J Ophthalmol 12: 909-914, 2019.

59. Campos-Mollo E, López-Garrido MP, Blanco-Marchite C, Garcia-Feijoo J, Peralta J, Belmonte-Martínez J, Ayuso C and Escribano J: CYP1B1 mutations in Spanish patients with primary congenital glaucoma: Phenotypic and functional variability. Mol Vis 15: 417-431, 2009.

60. Chavarria-Soley G, Sticht H, Aklillu E, Ingelman-Sundberg M, Pasutto F, Reis A and Rautenstrauss B: Mutations in CYP1B1 cause primary congenital glaucoma by reduction of either activity or abundance of the enzyme. Hum Mutat 29: 1147-1153, 2008.

61. Tran HT, Tran HT, Luong LH, Nguyen TS, Nguyen HQ, Vu TT, Ta TD, Dao TMA, Bui TH, Ta TV and Tran VK: Primary congenital glaucoma in Vietnam: Analysis and identification of novel CYP1B1 variants. Ophthalmic Genet 40: 286-287, 2019.

62. Khafagy MM, El-Guendy N, Tantawy MA, Eldaly MA, Elhilali HM and Wahab AHAA: Novel CYP1B1 mutations and a possible prognostic use for surgical management of congenital glaucoma. Int J Ophthalmol 12: 607-614, 2019.
63. Hilal L, Boutayeb S, Serrou A, Refass-Buret L, Shisseh H, Bencherifa F, El Mzibri M, Benazzouz B and Berraho A: Screening of CYP1B1 and MYOC in Moroccan families with primary congenital glaucoma: Three novel mutations in CYP1B1. Mol Vis 16: 1215-1226, 2010.

64. Dimasi DP, Hewitt AW, Straga T, Pater J, MacKinnon JR, Elder JE, Casey T, Mackey DA and Craig JE: Prevalence of CYP1B1 mutations in Australian patients with primary congenital glaucoma. Clin Genet 72: 255-260, 2007.

65. Libby RT, Smith RS, Savinova OV, Zabaleta A, Martin JE, Gonzalez FJ and John SW: Modification of ocular defects in mouse developmental glaucoma models by tyrosinase. Science 299: 1578-1581, 2003.

66. Lewis CJ, Hedberg-Buenz A, DeLuca AP, Stone EM, Alward WLM and Fingert JH: Primary congenital and developmental glaucomas. Hum Mol Genet 26: 28-36, 2017.

67. Zhao Y, Wang S, Sorenson CM, Teixeira L, Dubielzig RR, Peters DM, Conway SJ, Jefcoate CR and Sheibani N: Cyplb1 mediates periostin regulation of trabecular meshwork development by suppression of oxidative stress. Mol Cell Biol 33 4225-4240, 2013

68. Mookherjee S, Acharya M, Banerjee D, Bhattacharjee A and Ray K: Molecular basis for involvement of CYP1B1 in MYOC upregulation and its potential implication in glaucoma pathogenesis. PLoS One 7: 45077, 2012.

69. López-Garrido MP, Medina-Trillo C, Morales-Fernandez L, Garcia-Feijoo J, Martínez-de-la-Casa JM, García-Antón M and Escribano J: Null CYP1B1 genotypes in primary congenital and nondominant juvenile glaucoma. Ophthalmology 120: 716-723, 2013.

70. Alsaif HS, Khan AO, Patel N, Alkuraya H, Hashem M, Abdulwahab F, Ibrahim N, Aldahmesh MA and Alkuraya FS: Congenital glaucoma and CYP1B1: An old story revisited. Hum Genet 138: 1043-1049, 2019.

71. Li N,Zhou Y, Du L, Wei M and Chen X: Overview of Cytochrome P450 1B1 gene mutations in patients with primary congenital glaucoma. Exp Eye Res 93: 572-579, 2011.

72. Ou Z, Liu G, Liu W, Deng Y, Zheng L, Zhang S and Feng G: Bioinformatics analysis of CYP1B1 mutation hotspots in Chinese primary congenital glaucoma patients. Biosci Rep 38: BSR20180056, 2018.

73. Coêlho REA, Sena DR, Santa Cruz F, Moura BCFS, Han CC, Andrade FN and Lira RPC: CYP1B1 gene and phenotypic correlation in patients from Northeastern Brazil with primary congenital glaucoma. J Glaucoma 28: 161-164, 2019.

74. Rashid M, Yousaf S, Sheikh SA, Sajid Z, Shabbir AS, Kausar T, Tariq N, Usman M, Shaikh RS, Ali M, et al: Identities and frequencies of variants in CYP1B1 causing primary congenital glaucoma in Pakistan. Mol Vis 25: 144-154, 2019.

75. Waryah YM, Iqbal M, Sheikh SA, Baig MA, Narsani AK, Atif M, Bhinder MA, Ur Rahman A, Memon AI, Pirzado MS and Waryah AM: Two novel variants in CYP1B1 gene: A major contributor of autosomal recessive primary congenital glaucoma with allelic heterogeneity in Pakistani patients. Int J Ophthalmol 12: 8-15, 2019.

76. Talebi F, Mardasi FG, Asl JM and Lashgari A: Mutational spectrum of the CYP1B1 gene in Iranain primary congenital glaucoma family. Can J Ophthalmol 53: 87-89, 2018.

77. Sarfarazi M and Stoilov I: Molecular genetics of primary congenital glaucoma. Eye (Lond) 14: 422-428, 2000.

78. Wang SL, Piao SY, Xu MY, Zhang W, Ma JQ, Hao J, Chi H, Xue ZQ, Ha SP and Zhuang WJ: Evaluating correlation between the ocular biometry and genetic variants of MYOC and ABCA1 with primary angleclosure glaucoma in a cohort from northern China. Int J Ophthalmol 12: 1317-1322, 2019.

79. Nazir S, Mukhtar M, Shahnawaz M, Farooqi S, Fatima N, Mehmood R and Sheikh N: A novel single nucleotide polymorphism in exon 3 of MYOC enhances the risk of glaucoma. PLoS One 13: e0195157, 2018

80. Millá E, Mañé B, Duch S, Hernan I, Borràs E, Planas E, Dias Mde S, Carballo $M$ and Gamundi MJ; Spanish Multicenter Glaucoma Group-Estudio Multicéntrico Español de Investigación Genética del Glaucoma, EMEIGG: Survey of familial glaucoma shows a high incidence of cytochrome P450, family 1, subfamily B, polypeptide 1 (CYP1B1) mutations in non-consanguineous congenital forms in a Spanish population. Mol Vis 19: 1707-1722, 2013.

81. Lei L, Shushan L, Liu XY and Zhang C: Novel MYOC gene mutation in a Chinese family with primary open-angle glaucoma. Br J Ophthalmol: 1-6, 2019. 
82. Kaur K, Reddy AB, Mukhopadhyay A, Mandal AK, Hasnain SE Ray K, Thomas R, Balasubramanian D and Chakrabarti S: Myocilin gene implicated in primary congenital glaucoma. Clin Genet 67: 335-340, 2005.

83. Chakrabarti S, Kaur K, Rao KN, Mandal AK, Kaur I, Parikh RS and Thomas R: The transcription factor gene FOXC1 exhibits a limited role in primary congenital glaucoma. Invest Ophthalmol Vis Sci 50: 75-83, 2009.

84. Kim HJ, Suh W, Park SC, Kim CY, Park KH, Kook MS, Kim YY, Kim CS, Park CK, Ki CS and Kee C: Mutation spectrum of CYP1B1 and MYOC genes in Korean patients with primary congenital glaucoma. Mol Vis 17: 2093-2101, 2011.

85. Chen Y, Jiang D, Yu L, Katz B, Zhang K, Wan B and Sun X: CYP1B1 and MYOC mutations in 116 Chinese patients with primary congenital glaucoma. Arch Ophthalmol 126: 1443-1447, 2008.

86. Siggs OM, Souzeau E, Pasutto F, Dubowsky A, Smith JEH, Taranath D, Pater J, Rait JL, Narita A, Mauri L, et al: Prevalence of FOXC1 variants in individuals with a suspected diagnosis of primary congenital glaucoma. JAMA Ophthalmol 137: 348-355, 2019.

87. Smith RS, Zabaleta A, Kume T, Savinova OV, Kidson SH, Martin JE, Nishimura DY, Alward WL, Hogan BL and John SW: Haploinsufficiency of the transcription factors FOXC1 and FOXC2 results in aberrant ocular development. Hum Mol Genet 9: 1021-1032, 2000.

88. Chakrabarti S, Kaur K, Komatireddy S, Acharya M, Devi KR, Mukhopadhyay A, Mandal AK, Hasnain SE, Chandrasekhar G, Thomas R and Ray K: Gln48His is the prevalent myocilin mutation in primary open angle and primary congenital glaucoma phenotypes in India. Mol Vis 11: 111-113, 2005.

89. Medina-Trillo C, Aroca-Aguilar JD, Méndez-Hernández CD, Morales L, García-Antón M, García-Feijoo J and Escribano J: Rare FOXC1 variants in congenital glaucoma: Identification of translation regulatory sequences. Eur J Hum Genet 24: 672-680, 2016.

90. Rosbach J, Vossmerbaeumer U, Renieri G, Pfeiffer N and Thieme H: Osteogenesis imperfecta and glaucoma. A case report. Ophthalmologe 109: 479-82, 2012 (In German).

91. Mauri L, Uebe S, Sticht H, Vossmerbaeumer U, Weisschuh N, Manfredini E, Maselli E, Patrosso M, Weinreb RN, Penco S, et al Expanding the clinical spectrum of COL1A1 mutations in different forms of glaucoma. Orphanet J Rare Dis 11: 108, 2016.

92. Vithana EN, Aung T, Khor CC, Cornes BK, Tay WT, Sim X Lavanya R, Wu R, Zheng Y, Hibberd ML, et al: Collagen-related genes influence the glaucoma risk factor, central corneal thickness. Hum Mol Genet 20: 649-658, 2011.

93. Dimasi DP, Chen JY, Hewitt AW, Klebe S, Davey R, Stirling J, Thompson E, Forbes R, Tan TY, Savarirayan R, et al: Novel quantitative trait loci for central corneal thickness identified by candidate gene analysis of osteogenesis imperfecta genes. Hum Genet 127: 33-44, 2010.

94. Liang X, Zhang L, Ji Q, Wang B, Wei D and Cheng D: miR-421 promotes apoptosis and suppresses metastasis of osteosarcoma cells via targeting LTBP2. J Cell Biochem 120: 10978-10987, 2019.

95. Suri F, Yazdani S and Elahi E: LTBP2 knockdown and oxidative stress affect glaucoma features including TGF $\beta$ pathways, ECM genes expression and apoptosis in trabecular meshwork cells. Gene 673: 70-81, 2018.

96. Narooie-Nejad M, Paylakhi SH, Shojaee S, Fazlali Z, Rezaei Kanavi M, Nilforushan N, Yazdani S, Babrzadeh F, Suri F, Ronaghi M, et al: Loss of function mutations in the gene encoding latent transforming growth factor beta binding protein 2 , LTBP2, cause primary congenital glaucoma. Hum Mol Genet 18: 3969-3977, 2009.

97. Ali M, McKibbin M, Booth A, Parry DA, Jain P, Riazuddin SA, Hejtmancik JF, Khan SN, Firasat S, Shires M, et al: Null mutations in LTBP2 cause primary congenital glaucoma. Am J Hum Genet 84: 664-671, 2009.

98. Morlino S, Alesi V, Calì F, Lepri FR, Secinaro A, Grammatico P, Novelli A, Drago F, Castori M and Baban A: LTBP2-related 'Marfan-like' phenotype in two Roma/Gypsy subjects with the LTBP2 homozygous p.R299X variant. Am J Med Genet A 179: 104-112, 2019.

99. Challa P, Hauser MA, Luna CC, Freedman SF, Pericak-Vance M, Yang J, McDonald MT and Allingham RR: Juvenile bilateral lens dislocation and glaucoma associated with a novel mutation in the fibrillin 1 gene. Mol Vis 12: 1009-1115, 2006.
100. Yang Y, Zhang L, Li S, Zhu X and Sundaresan P: Candidate gene analysis identifies mutations in CYP1B1 and LTBP2 in Indian families with primary congenital glaucoma. Genet Test Mol Biomarkers 21: 252-258, 2017.

101. Micheal S, Siddiqui SN, Zafar SN, Iqbal A, Khan MI and Hollander AID: Identification of novel variants inLTBP2andPXDNUsing whole-exome sequencing in developmental and congenital glaucoma. PLoS One 11: e0159259, 2016.

102. Kuehn MH, Lipsett KA, Menotti-Raymond M, Whitmore SS, Scheetz TE, David VA, O'Brien SJ, Zhao Z, Jens JK, Snella EM, et al: Correction: A mutation in LTBP2 causes congenital glaucoma in domestic cats (Felis catus). PLoS One 11: $\mathrm{e} 0161517,2016$.

103. Inoue T, Ohbayashi T, Fujikawa Y, Yoshida H, Akama TO, Noda K, Horiguchi M, Kameyama K, Hata Y, Takahashi K, et al: Latent TGF- $\beta$ binding protein- 2 is essential for the development of ciliary zonule microfibrils. Hum Mol Genet 23: 5672-5682, 2014.

104. Ma AS, Grigg JR and Jamieson RV: Phenotype-genotype correlations and emerging pathways in ocular anterior segment dysgenesis. Hum Genet 138: 899-915, 2019.

105. Coleman AL and Miglior S: Risk factors for glaucoma onset and progression. Sur Ophthalmol 53 (Suppl 1): S3-S10, 2008.

106. Krishnakumar K, Margaret R, Marchant JK, Stephen H and John SW: Schlemm's canal is a unique vessel with a combination of blood vascular and lymphatic phenotypes that forms by a novel developmental process. PLoS Biol 12: e1001912, 2014.

107. Aspelund A, Tammela T, Antila S, Nurmi H, Leppänen VM, Zarkada G, Stanczuk L, Francois M, Mäkinen T, Saharinen P, et al: The Schlemm's canal is a VEGF-C/VEGFR-3-responsive lymphatic-like vessel. J Clin Invest 124: 3975-3986, 2014.

108. Saharinen P, Eklund L and Alitalo K: Therapeutic targeting of the angiopoietin-TIE pathway. Nat Rev Drug Dis 16: 635-661, 2017.

109. Partanen J, Armstrong E, Mäkelä TP, Korhonen J, Sandberg M, Renkonen R, Knuutila S, Huebner K and Alitalo K: A novel endothelial cell surface receptor tyrosine kinase with extracellular epidermal growth factor homology domains. Mol Cell Biol 12: 1698-1707, 1992.

110. Limaye N, Wouters V, Uebelhoer M, Tuominen M, Wirkkala R, Mulliken JB, Eklund L, Boon LM and Vikkula M: Somatic mutations in angiopoietin receptor gene TEK cause solitary and multiple sporadic venous malformations. Nat Genet 41: 118-124, 2009.

111. Suri C, Jones PF, Patan S, Bartunkova S, Maisonpierre PC, Davis S, Sato TN and Yancopoulos GD: Requisite role of angiopoietin-1, a ligand for the TIE2 receptor, during embryonic angiogenesis. Cell 87: 1171-1180, 1996.

112. Barton WA, Dalton AC, Seegar TCM, Himanen JP and Nikolov DB: Tie2 and Eph receptor tyrosine kinase activation and signaling. Cold Spring Harb Perspect Biol 6: a009142, 2014.

113. Kesler CT, Pereira ER, Cui CH, Nelson GM, Masuck DJ, Baish JW and Padera TP: Angiopoietin-4 increases permeability of blood vessels and promotes lymphatic dilation. FASEB J 29: 3668-3677, 2015.

114. Elamaa H, Kihlström M, Kapiainen E, Kaakinen M, Miinalainen I, Ragauskas S, Cerrada-Gimenez M, Mering S, Nätynki M and Eklund L: Angiopoietin-4-dependent venous maturation and fluid drainage in the peripheral retina. Elife 7: e37776, 2018.

115. Thomson BR, Heinen S, Jeansson M, Ghosh AK, Fatima A, Sung HK, Onay T, Chen H, Yamaguchi S, Economides AN, et al: A lymphatic defect causes ocular hypertension and glaucoma in mice. J Clin Invest 124: 4320-4324, 2014.

116. Thomson BR, Souma T, Tompson SW, Onay T, Kizhatil K, Siggs OM, Feng L, Whisenhunt KN, Yanovitch TL, Kalaydjieva L, et al: Angiopoietin-1 is required for Schlemm's canal development in mice and humans. J Clin Invest 127: 4421-4436, 2017.

117. Souma T, Tompson SW, Thomson BR, Siggs OM, Kizhatil K, Yamaguchi S, Feng L, Limviphuvadh V, Whisenhunt KN, Maurer-Stroh S, et al: Angiopoietin receptor TEK mutations underlie primary congenital glaucoma with variable expressivity. J Clin Invest 126: 2575-2587, 2016.

This work is licensed under a Creative Commons Attribution-NonCommercial-NoDerivatives 4.0 International (CC BY-NC-ND 4.0) License. 